\title{
FEASIBILITY OF SELF-SEPARATION AND SEQUENCING DURING GPS INSTRUMENT APPROACHES
}

\author{
Ermin Ramiscal, Jennifer Murdoch, Ph.D., Jennifer McNabb \\ NASA Langley Research Center, Hampton, VA \\ Frank Bussink, National Institute of Aerospace, City, Hampton, VA
}

\begin{abstract}
The Self-Separation and Sequencing (SSS) Flight Experiment was conducted by the National Aeronautics and Space Administration (NASA) Langley Research Center (LaRC) to determine if instrument rated general aviation (GA) pilots could self-separate and sequence their ownship aircraft, while following a simulated aircraft, into a simulated non-towered, non-radar airport during simulated Instrument Meteorological Conditions (IMC). Six GA pilots' subjective workload levels and abilities to fly a Cirrus SR22X aircraft while performing self-separation and sequencing procedures during straight-in, intrail approaches and approaches with simultaneous arrivals of aircraft were examined. This paper discusses the results of the flight experiment and its relevance to future research.
\end{abstract}

\section{Introduction}

\section{Problem Statement}

Although a capacity plateau has been reached within the United States for the commercial air transportation system and the National Airspace System (NAS), demand for air transportation services continues to increase. An approach to increasing total air transportation system capacity and throughput is to enhance access to more than 5,000 underutilized smaller airports located within the U.S. The majority of these smaller airports have no control towers and lie outside Air Traffic Control (ATC) radar coverage, and as a result, are not suitable for use by the airlines that currently provide most of the nation's air transportation service. However, such airports have the potential to provide convenient access and service to communities across the country [1].

\section{SATS Solution}

NASA, partnered with the Federal Aviation Administration (FAA) and the National Consortium for Aviation Mobility (NCAM) (i.e., a consortium of U.S. industries, local and state governments, and research institutions including universities), is leading a research and development program focused on maturing technologies needed for a Small Aircraft Transportation System (SATS) [2]. The long-term goal of SATS is to facilitate equitable, on-demand, widely distributed access to more communities in less time [2]. The near-term, five-year goal of the SATS Program is to "develop key airborne technologies [and procedures] that permit small aircraft operations during near allweather conditions at and to virtually any touchdown zone at thousands of landing facilities (including small airports) in the United States." [1].

\section{SATS Higher Volume Operations (HVO) Objective}

The SATS Program's initial focus is to prove that four new operating capabilities will enable safe and affordable access to virtually any runway in the nation during most weather conditions. The four SATS Program objectives center on enabling operational capabilities that enhance operational efficiency in the current NAS environment. These objectives include:

- Higher Volume Operations (HVO) at Non-Towered, Non-Radar Airports;

- Lower Landing Minimums at Minimally Equipped Landing Facilities;

- Increased Single-Pilot Crew Safety and Mission Reliability; and

- En Route Procedures and Systems for Integrated Fleet Operations. 
This paper addresses part of the first of these new operating capabilities, Higher Volume Operations (HVO). The SATS HVO Concept of Operations (Con Ops) proposes to dramatically increase operating capacity during IMC at nontowered, non-radar equipped airports by enabling simultaneous operations of multiple aircraft.

Currently, NAS capacity is limited at nontowered, non-radar airports during poor weather because ATC procedural separation limits airport capacity to one aircraft operation at a time (i.e., single takeoff/departure or single approach/arrival). Therefore, the overall goal of the SATS HVO subelement is to increase capacity by enabling the simultaneous operation of multiple aircraft in nonradar airspace at and around small non-towered airports in nearly all weather conditions.

Two fundamental aspects of the SATS HVO Con Ops include a Self Controlled Area (SCA) and an Airport Management Module (AMM) [3]. The SCA is airspace that is established at a "SATS airport" (i.e., a non-towered, non-radar equipped airport) during IMC. Within the SCA, pilots are responsible for self-separation from other aircraft and for sequencing themselves onto the approach. Automatic Dependent Surveillance - Broadcast (ADS-B) is required by participating aircraft and will allow the Cockpit Display of Traffic Information (CDTI) to enable self-separation. This self-separation capability will allow the throughput associated with these types of airports to increase by eliminating the need for ATC's procedural separation. The AMM is an automated ground module located at a SATS airport that will provide information regarding SCA status (i.e., active or inactive) as well as sequence number information to arriving aircraft (so they can sequence themselves onto the approach). Flight within the SCA will be governed by a set of rules and procedures rather than by the AMM. Two primary conditions necessary for the success of the SATS HVO Con Ops were as follows:

- Pilots must be able to self-sequence for an instrument approach; and

- They must be able self-separate before and during the approach.
The employment of separation standards for the SSS Flight Experiment was based on those that ATC has established for aircraft operating on instrument flight rules (IFR) flight plans, lower than $18,000 \mathrm{ft}$ within a radar environment. When aircraft operated at the same altitude, a minimum of 3 nautical miles (NM) separation was required. In the SSS Flight Experiment, 3 NM separation was required either longitudinally (intrail) or laterally. Since both values were the same for this experiment, hereafter the term lateral separation will refer to both longitudinal and lateral separation. When aircraft were within $3 \mathrm{NM}$ laterally or vertically of each other, a $1000 \mathrm{ft}$ minimum vertical separation was required. During this experiment, pilots were deemed to be vertically separated (within $3 \mathrm{NM}$ of traffic) if they remained separated from the traffic aircraft by at least $825 \mathrm{ft}$. This altitude difference occurred as a result of the \pm 100 $\mathrm{ft}$ allowance in the FAA Instrument Rating Practical Test Standards (PTS) and an allowable $\pm 75 \mathrm{ft}$ error in the ownship altimeter [4]. There was no altitude allowance for the virtual aircraft since it "flew" without error.

The SSS Flight Experiment collected quantitative and qualitative data to determine if GA pilots, asked to hand fly an aircraft while using a CDTI and related SATS HVO procedures, could perform self-separation and sequencing tasks without experiencing detrimental effects on their perceived workload level and ability to fly an instrument approach. The results of this experiment support the overall viability of the SATS HVO Con Ops of simultaneous operations of multiple aircraft during IMC at non-towered, non-radar equipped airports [3].

\section{Research Objectives}

The first objective of the SSS Flight Experiment was to determine if a GA pilot can use a CDTI, to self-separate and sequence his/her ownship aircraft, while following a simulated aircraft, into a simulated non-towered, non-radar equipped airport during simulated IMC. To answer this question, six GA pilots were asked to hand fly an aircraft according to the SATS HVO procedures defined for straight-in, intrail approaches as well as "simultaneous arrival" approaches (i.e., approaches requiring aircraft to merge). The overall viability of 
the above stated additional tasks was evaluated in terms of percentage of time that separation and appropriate landing sequence were maintained.

The second objective of the SSS Flight Experiment was to assess how a pilot's workload and ability to fly an aircraft are affected when he/she uses a CDTI to self-separate and sequence his/her ownship aircraft into a simulated nontowered, non-radar equipped airport during simulated IMC. Subjective measures of workload and objective measures of flight path parameter deviation were recorded while pilots performed the SATS HVO approach procedures. Participants' workload and flying proficiency levels were also measured when they performed straight-in, intrail approaches and simultaneous arrival approaches according to current day procedures so that a baseline of each pilot's flying proficiency could be established.

\section{Method}

\section{Participants}

Participants consisted of six GA pilots; all were instrument rated and current to fly under IFR. All participants had less than 350 total flight hours $(\mathrm{M}=275.83, \mathrm{SD}=52.19)$, and on average, they had flown approximately $29 \mathrm{hrs}$ during the last 90 days.

\section{Test Facilities and Apparatus}

\section{Test Aircraft}

The test aircraft used for this experiment was NASA LaRC's Cirrus SR22X research aircraft (shown in Figure 1).

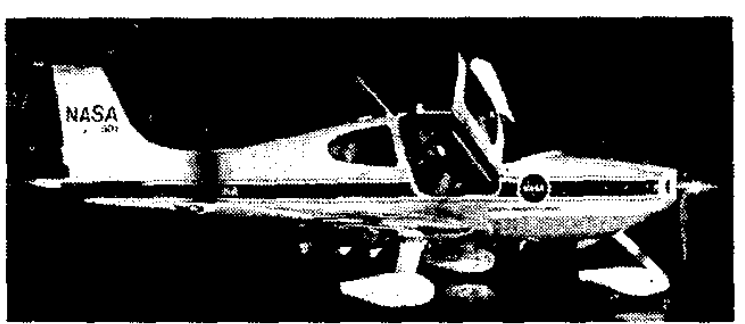

Figure 1. NASA LaRC's Cirrus SR22X Research Aircraft.

The SR22X is a four-place, composite, fixedgear aircraft with a single 310 -horsepower piston engine. It is one of several new-generation GA aircraft making use of the latest in materials, aerodynamics, avionics, and manufacturing technology [5].

Subject pilots flew the assigned experiment tasks from the left-side pilot's seat, while a NASA safety pilot flew at all other times from the right seat. An experimenter occupied the right aft seat and operated experiment equipment located in the aft area of the aircraft.

\section{Airborne Research Software}

The airborne research software served as a main component of the flight experiment in that it:

- Generated each approach scenario;

- Generated traffic aircraft for the subject pilot to follow;

- Performed calculations and generated displays to enable the self-separation and self-sequencing tasks;

- Generated the displays on the MultiFunction Display (MFD);

- Detected potential conflicts (3 NM laterally or $825 \mathrm{ft}$ vertically) between the SR22X and simulated traffic aircraft;

- Generated visual and audio alerts associated with traffic conflicts;

- Generated visual information intended to assist the subject pilot in the prevention of traffic conflicts; and

- Logged scenario start time, scenario stop time, and information regarding loss of separation (lateral and vertical) between the SR22X and simulated traffic aircraft.

\section{Traffic Generator}

Traffic aircraft generation software was required to simulate a traffic aircraft from which subject pilots could self-separate their ownship aircraft. The National Aerospace Laboratory's (NLR) traffic manager software, referred to as "TMX (Traffic Manager Executable)," provided traffic generation and served as the main basis of the airborne research software utilized by the SSS Flight Experiment [6].

The TMX software facilitated the development of flight scenarios by allowing the experimenters to specify the performance of traffic aircraft associated 
with each scenario as well as the traffic aircraft's flight profile (i.e., its start position, heading, altitude, calibrated airspeed, and all subsequent waypoints, altitudes, and airspeeds). To add realism, the traffic aircraft flew the scenario in the same winds aloft conditions that the ownship aircraft encountered. Each flight scenario also included the start point of the data run for each scenario such that when the subject pilot flew within a specified lateral distance and altitude of the start waypoint, the scenario automatically began. The aforementioned capabilities of TMX enabled a consistent presentation of traffic aircraft among all subject pilots. The "straight-in, intrail" scenarios were optimized so that when the traffic aircraft landed, the ownship aircraft was $3.5 \mathrm{NM}$ plus 30 $\mathrm{sec}$ from the runway threshold. The "simultaneous arrival" scenarios were optimized so that both the traffic and lead aircraft arrived over the Intermediate Fix (IF) on the approach at the same time. These two approach types are described in the "Independent Variables" section.

TMX was also capable of detecting conflicts, generating visual and audio alerts, and generating conflict prevention information. As described in the "Independent Variables" section, one of the display types included in the SSS Flight Experiment [i.e., Method of Separation (MAS) 2] made use of TMX's Conflict Detection, Alerting and Prevention (CDAP) capabilities. Independent display software served as the interface between TMX and the MFD as well as between TMX and the Air Data, Attitude and Heading Reference System (ADAHRS) [7, 8]. The display software presented the three display types (on the MFD) described in the "Independent Variables" section.

The CDTI used in this flight experiment had an update rate identical to the update rate that would have been experienced if the test aircraft's avionics were receiving ADS-B information. Furthermore, because the subject pilots selfseparated from the virtual traffic during simulated IMC, a subject pilot would not be aware of any presentation differences between the display of a virtual traffic aircraft or an actual traffic aircraft.

As described below, two critical enhancements were made to the TMX software to enable SATS HVO operations for self-sequencing and separation.

\section{Sequencing}

The first main enhancement to the TMX software was the addition of the capability to initialize both the ownship and the traffic aircraft with a starting sequence number [9]. The sequence number identified the lead aircraft and the following aircraft. In all test conditions, the ownship aircraft was to follow the traffic aircraft on a GPS instrument approach into the destination airport. Hence, each test condition began with the traffic aircraft having "Sequence \#1" and the ownship aircraft having "Sequence \#2." These starting sequence numbers were scripted into each flight scenario. With "Sequence \#2," the subject pilot was responsible for sequencing himself behind the lead aircraft and maintaining at least minimum separation distance or altitude from the lead aircraft at all times until the self-separation task ended with the ownship receiving "Sequence \#1."

\section{Self-Separation}

The other main enhancement to the TMX software (hereafter called research software) enabled self-separation operations during the flight experiment [9]. This enhancement consisted of two main components: a Requested Time of Arrival (ReTA) calculation and a Proceed/Hold calculation.

The ReTA was an internal calculation, not presented to the pilot, that determined the earliest clock time (GMT), after which the ownship aircraft could depart the IF inbound on the approach and be reasonably assured of proper lateral separation from the traffic aircraft throughout the approach. The minimum lateral separation required throughout the approach was $3 \mathrm{NM}$.

The research software calculated ReTA based on the speed profiles of the traffic aircraft and the ownship aircraft. The traffic and ownship aircraft had two speeds that were planned to be flown during the approach (i.e., a constant airspeed up to the FAF, followed by a speed reduction to final approach speed to the runway threshold). Once the lead aircraft had arrived within close proximity of the IF inbound (in terms of heading and distance), the research software, using the actual winds aloft derived by research software onboard the ownship aircraft and the planned speed profile of the lead aircraft, calculated the lead aircraft's estimated time of arrival (ETA) at the runway threshold. Then the software, based on the planned speed profile of the 
ownship aircraft and derived winds aloft, calculated the estimated time enroute (ETE) of the ownship aircraft from the IF to the minimum lateral separation point plus a $0.5 \mathrm{NM}$ margin (i.e., $3.5 \mathrm{NM}$ from the runway threshold). This ETE was subtracted from the lead aircraft's ETA. Finally, an additional $30 \mathrm{sec}$ were added to the ReTA to create an additional margin for pilot error. The resulting time was the ReTA for the ownship aircraft. For simplification, during all calculations, an instantaneous speed reduction by all aircraft was assumed at the speed reduction point.

If the ownship aircraft accelerated or decelerated inbound to the IF, a new ReTA was calculated using the new speed. In short, the ReTA; with some margin for error, was calculated to help ensure at least a minimum lateral separation of 3 $\mathrm{NM}$ at the planned closest point of approach (i.e., when the lead aircraft crossed the threshold). For a faster ownship aircraft, its ReTA would be later than a slower aircraft to ensure the same minimum separation when the lead aircraft crossed the threshold.

To ease the workload of pilot mental calculations aloft, a simple tool was developed to assist the pilot in determining whether he had enough separation to begin the approach (i.e., using ReTA). This tool instructed the pilot, via the MFD, to either "Proceed" (on the approach with proper separation) or "Hold" (until proper separation could be guaranteed).

Instead of displaying the ReTA to the subject pilot, the research software calculated the ETA of the ownship aircraft at the IF. If the ETA was later than the ReTA, then the text "Proceed" was displayed to the subject pilot, and the subject pilot could fly over the IF waypoint inbound for the instrument approach. If the ETA was earlier than ReTA, then the text "Hold" was displayed to the subject pilot, and the subject pilot was required to hold until receiving the "Proceed" indication from the software. This eased the workload of the subject pilots so that they only needed to add the "Proceed/Hold" display to their instrument scan. The SATS HVO Con Ops was not optimized to maximize the number of aircraft per hour into the airport; instead, it was only intended to increase the capacity of the airport during IMC. It is important to note that the purpose of the Proceed/Hold tool was not to achieve a certain spacing between aircraft, but to help ensure that separation could be maintained throughout the approach.

\section{Other Airborne Equipment}

NASA LaRC's Cirrus SR22X was modified by the addition of a GA baseline research system, which included an additional power system to power the research systems; an ADAHRS; an experimenter workstation; an Avidyne MFD; a Data Acquisition System (DAS); a sensor system; an air data boom; two general-purpose computers; a video system; and an audio system [5]. Much of this equipment was mounted on the research equipment pallet located in the aircraft's aft compartment. For the SSS Flight Experiment, specific modifications to the GA baseline research system included the addition of experiment specific software on the general-purpose computers, an additional audio channel for experimenter comments, and custom Jeppesen database cards for the Garmin 430 GPS.

For ease of implementation on the test aircraft, custom Approach Database cards containing SATS HVO approach information were developed in conjunction with Jeppesen Sanderson, Inc. for use in the standard dual Garmin GNS 430 GPS/communication/navigation units installed onboard the SR22X. These cards enabled the subject pilots to fly the SATS HVO approaches using the SR22X's standard instrumentation with little additional training. Although these approaches were to virtual airports, the responses of the avionics (as flown by subject pilots) were the same as if the approaches had been to actual airports.

\section{In-Flight Materials}

FAA-style approach charts, depicting the SATS HVO Instrument Approach Procedure (IAP) were developed in-house to assist subject pilots with the performance of the experiment's GPS instrument approaches. The IAP charts provided a graphic presentation to the pilot of: 1) holding procedures (if required prior to commencing the instrument approach); 2) the instrument approach procedure; and 3) the missed approach procedure.

The IAP presented to all pilots a flight path (lateral position and altitude) to execute an instrument approach. When combined with sequencing information, the IAP flight path allowed an arriving SATS HVO pilot to anticipate the 
actions of the traffic aircraft, thereby improving the pilot's ability to self-separate from and sequence with that traffic. Since the flight path was fixed by the IAP, the only degree of freedom available to the pilot during the approach was airspeed. However, all SATS HVO aircraft had an established airspeed profile that should have been flown.

The SATS HVO IAP was contained within the SCA and thus SATS HVO pilots were responsible for self-sequencing and self-spacing themselves from each other. For the SSS Flight Experiment, the purpose of the SATS HVO IAP was to enable SATS HVO pilots to self-separate and sequence themselves. The SATS HVO IAP was identical to the FAA IAP except that a mandatory holding pattern, $1000 \mathrm{ft}$ above the main procedure course, was established over the IF, and those aircraft on the main procedure course were required to cross the IF at the appropriate altitude. The SATS HVO IAP directed an arriving SATS HVO aircraft into the holding pattern above the IF. A SATS HVO pilot would then wait for a "Proceed" message in order to leave the hold and descend to the main procedure course to fly the approach. Also, if an arriving aircraft (inbound to the IF) was far enough intrail behind the lead aircraft to receive the "Proceed" message (or already had "Sequence \#1"), the pilot did not need to enter the holding pattern; instead he could descend to the main procedure course to fly the approach. So, the research software's "Proceed/Hold" messages assisted the pilot in choosing the appropriate part of the IAP to fly (i.e., holding procedure, or main procedure course).

\section{Ground Simulation Software}

To perform the functions necessary to conduct the flight experiment, the airborne research software required ownship aircraft values for the following parameters: aircraft ground speed, track, heading, latitude, longitude, wind speed, wind direction, altitude, airspeed, and vertical velocity. Onboard the aircraft, the ADAHRS provided the values of these parameters. The commercially available flight simulation software X-Plane was used to test the research software prior to installation on the aircraft [10]. X-Plane's Cirrus SR20 aircraft model was used to simulate the ownship SR22X aircraft [11]. Additionally, an XPlane interface developed specifically for the research software allowed output parameters from $\mathrm{X}$-Plane to drive the research software as if it were airborne on the actual aircraft. Using the X-Plane simulation software, the research software was tested with the flight hardware, including the general-purpose computers and the Avidyne MFD, in the NASA LaRC Flight Systems Integration Laboratory (FSIL). The final ground software checkout was performed using X-Plane to drive the research software installed in the flight hardware onboard the SR22X.

\section{Test Areas}

To minimize the interference of nonparticipating aircraft with data runs, the data runs were performed at a minimum of $2000 \mathrm{ft}$ above ground level (AGL), using virtual GPS instrument approaches, instead of into an airfield. To maximize flexibility with winds aloft, approaches to two perpendicular runways were developed. The flight experiment's GPS instrument approaches were developed using the FAA's standard terminal arrival area (TAA) criteria as an initial starting point [12]. Depending on wind direction and traffic, one of four different GPS instrument approaches was selected by the onboard experimenter. Each GPS approach's waypoints were determined using Jeppesen's FlightMap software [13].

\section{Experiment Design}

The experiment design used for data collection was a 2 (Approach Type) $\times 3$ (Display Type), within-subject design in which the same six subjects were assigned to each experimental cell (i.e., test condition).

\section{Independent Variables}

The two independent variables used in the experiment design were display type and approach type. Each test condition involved asking subject pilots to fly the SR22X with a given combination of display type and approach type.

\section{Display Type}

The three display types included: 1) Baseline, 2) Method of Approach Separation (MAS) 1, and 3) MAS 2. The Baseline display represented the type of navigation display found in some of the current new-generation GA aircraft. The MAS 1 and 
MAS 2 displays were "SATS HVO display types" employed in the experiment to determine the feasibility of asking GA pilots to perform selfseparation and sequencing tasks. These two displays were included as levels of the display type independent variable so that the feasibility of performing the experiment's tasks using each display could be evaluated. All three displays were generated on the MFD by one of the test aircraft's general-purpose computers.

Baseline display. An advanced display was chosen as the baseline display so that the effect of the additional tasks of self-separation and sequencing could be isolated from the effects of the winds aloft display, the track display, and the flight plan display. As shown in Figure 2, components of the Baseline display included:

- Ownship depicted by the aircraft symbol located in the center of the compass rose;

- Current magnetic heading of the aircraft shown at the top of the compass rose;

- Winds aloft shown in the upper left of the compass rose (magnetic wind direction and speed were shown as text, and an arrow provided a visual representation with respect to the ownship heading);

- Range ring and a dashed circle in the middle of the compass rose serving as a range scale indicating half of the full scale for the display with the value shown in the top and bottom of the range circle (i.e., $5 \mathrm{NM}$ range of a 10 NM display);

- A magenta line representing the flight plan with waypoints or the lateral approach path with respect to the ownship aircraft;

- A green dashed line extending from the ownship aircraft representing a track line that was the actual ground track of the aircraft due to the winds aloft; and

- A standard GPS holding pattern displayed at the IF (when selected by the pilot during simultaneous approaches).

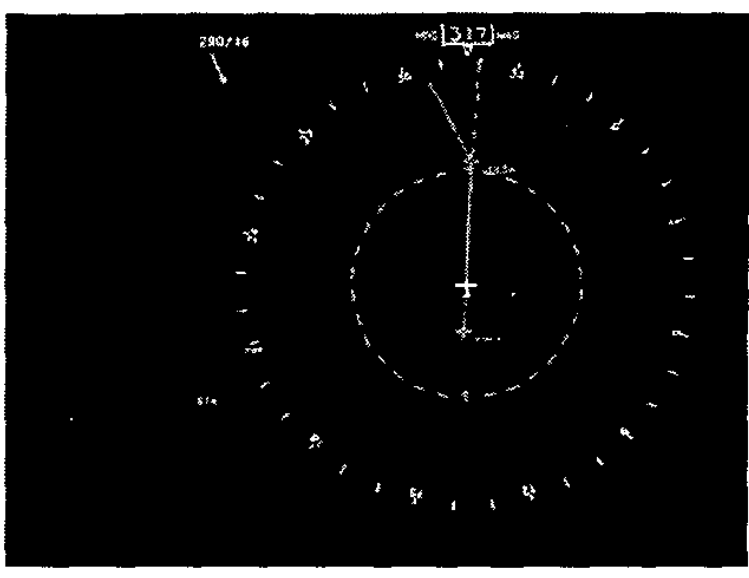

Figure 2. Baseline Dìsplay

MAS 1 display. The MAS 1 display (shown in Figure 3) had all of the elements of the Baseline display with several important additions necessary for the subject pilot to perform self-separation and maintain appropriate sequencing. The most significant difference between the MAS 1 display and the Baseline display was that the traffic aircraft's position, track, and altitude were shown on the MAS 1 display. A chevron represented the traffic aircraft with the tip pointed in the direction of the ground track, and the circle around the traffic aircraft represented the minimum lateral distance that the subject pilot had to maintain in order to remain separated.

Traffic aircraft information included sequence number, estimated indicated airspeed, relative altitude, aircraft type and call sign. The ownship aircraft sequence number was depicted as text in two places. The "Proceed/Hold" text was shown beneath the sequence number, and the digital Automated Traffic Information System (ATIS) for the arrival airport was displayed beneath the "Proceed/Hold" text. 


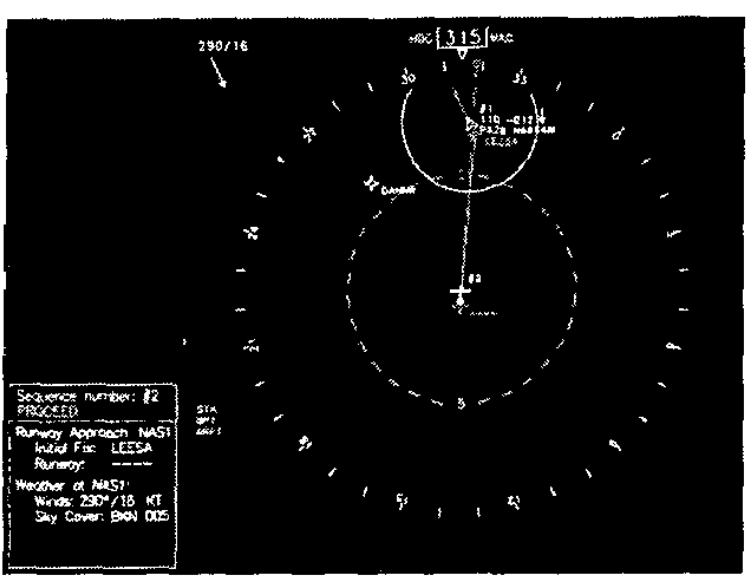

Figure 3. MAS 1 Display

MAS 2 display. The difference between the MAS 2 display (shown in Figure 4) and the MAS 1 display was the addition of CDAP information. When a conflict (i.e., loss of separation) was predicted to occur in less than $60 \mathrm{sec}$, visible and audible alerts were presented, and conflict prevention information was provided. Primary conflict prevention information, related to airspeed and vertical speed, was depicted as bands on the MFD's representations of the airspeed and vertical speed indicators. To avoid a conflict, a subject pilot had to keep the aircraft from flying within the depicted "conflict prevention bands."

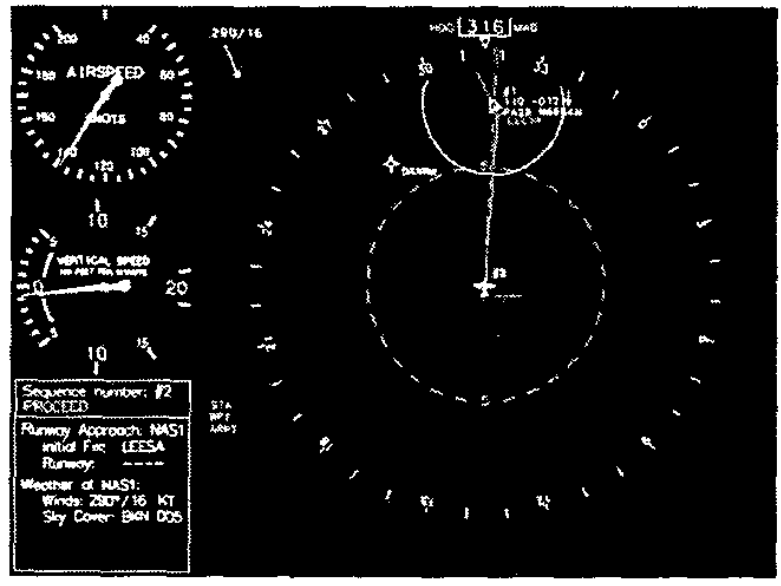

Figure 4. MAS 2 Display

\section{Approach Type}

The approach type was either: 1) a straight-in, intrail approach, or 2) a simultaneous arrival approach. During a straight-in, intrail approach, the subject pilot could proceed direct to the IF and fly the approach without any major changes in heading. The subject pilot's task involved maintaining at least the minimum lateral separation while following the lead aircraft on the approach.

During a simultaneous arrival approach, the scenarios were designed so that the ownship aircraft would nearly arrive at the same waypoint (IF) as the lead aircraft. This forced the subject pilot to maintain a vertical separation from the traffic and also forced him to fly a holding pattern until receiving the "Proceed" message.

The self-separation task for both types of approaches ended when the ownship aircraft received the indication that they had "Sequence \#1" for the airport. This message was received after the lead aircraft had cleared the runway.

\section{Dependent Measures}

\section{Separation Breaches and Landing Sequence Blunders}

For each scenario involving SATS HVO procedures, subject pilots were instructed to maintain at least $3 \mathrm{NM}$ or $1000 \mathrm{ft}$ of separation between their ownship aircraft and simulated traffic aircraft and were instructed to maintain landing sequence $\# 2$ at all times. Frequency counts and durations (i.e., elapsed times) of separation breaches and landing sequence blunders were collected to enable the calculation of the percentage of time that separation and appropriate landing sequence were maintained.

\section{Lateral (Intrail) Separation between Ownship Aircraft and Traffic Aircraft at Termination of the Self-Separation Task}

For each SATS HVO scenario, the time that the traffic (i.e., lead aircraft) landed was recorded and later defined as the official completion moment of the scenario run. At this point in time, it was critical to determine the position of the ownship aircraft to confirm, along with the flight logging software, that self-separation had been maintained intrail while performing the SATS HVO procedures. The ownship aircraft flew at higher approach speeds than the lead aircraft; this resulted in a rate of closure between the ownship and lead aircraft with the closest point of approach intrail occurring at the termination of the self-separation task (i.e., when the lead aircraft landed). So, for 
each SATS HVO scenario, the barometric altitude and distance to waypoint parameters were recorded at the final completion moment of each data collection run. This information was compiled for the SATS HVO scenario to verify the final position of the test aircraft and to allow for a more detailed determination of the lateral (intrail) separation distance between the ownship aircraft and the virtual traffic aircraft.

\section{Flight Path Parameter Deviation}

Flight path parameter deviation data were collected using the DAS to assess overall flight path accuracy and to assess the subject pilots' capabilities to perform the additional tasks of selfseparation and sequencing while flying a GPS instrument approach during simulated IMC. At the beginning of each flight task, subject pilots were given explicit values for altitude, airspeed, vertical speed, and cross track error (XTE) and were asked to hold these values as closely as possible during flight. All of these parameters have established standards published in the FAA's Instrument Rating PTS [4].

\section{Subjective Assessments of Workload}

Subjective assessments of workload were obtained through the use of the Air Force Flight Test Center's (AFFTC) Seven-Point Subjective Workload Estimate Scale and the Modified CooperHarper Rating Scale $[14,15]$. At the end of each test condition, subject pilots were asked to provide an AFFTC workload estimate and complete a Modified Cooper-Harper Rating Scale form.

\section{Procedure}

Each subject pilot individually completed a pre-experiment session, a "classroom" training session, an "in-the-aircraft" training session, a familiarization flight, four experiment flights (during which subject pilots completed each of the six test conditions twice), and a post-experiment debriefing session. Each subject pilot participated in the experiment over the course of approximately three, eight and a half hour days.

\section{Results and Discussion}

\section{Separation Breaches and Landing Sequence Blunders}

At no time did any of the SSS Flight Experiment's subject pilots lose separation with the lead aircraft or fail to maintain their assigned sequence number. Subject pilots successfully selfseparated and self-sequenced 100 percent of the time during the data runs. This finding supports the assertion that GA pilots can use a CDTI and related SATS HVO procedures to self-separate and sequence their ownship aircraft, while following a simulated aircraft, into a simulated non-towered, non-radar equipped airport during simulated IMC.

\section{Lateral Separation between Ownship Aircraft and Traffic Aircraft at Termination of the Self-Separation Task}

The minimum intrail separations experienced during the approaches requiring self-separation did not come close to $3 \mathrm{NM}$, the minimum separation required. Subject pilots maintained at least minimum lateral separation during the intrail portion of the approach between the IF and the MAP.

\section{Flight Path Parameter Deviation}

Flight path parameter deviation data consisted of deviations from assigned altitude, airspeed, vertical velocity, and course (or XTE). For each subject pilot, one root mean squared error (RMSE) value was calculated for each parameter using the data recorded during a single test condition. RMSE values were analyzed using a series of 2 (Approach Type) $x 3$ (Display Type) repeated measures Analysis of Variance (ANOVA) tests; that is, one AVOVA was performed in conjunction with each parameter $[16,17,18]$.

The results of the ANOVAs revealed that subject pilots maintained assigned altitudes, vertical velocity, and course equally well when they performed straight-in, intrail approaches and when they performed simultaneous arrival approaches ( $p$ $>0.05$ ); when they performed approaches using the Baseline display, the MAS 1 display, and the MAS 2 display $(p>0.05)$; and when they performed 
different approach types using different types of displays $(p>0.05)$. At a statistically significant level, subject pilots maintained assigned airspeeds more accurately during simultaneous arrival approaches than during straight-in, intrail approaches $(p<0.05)$; however, a mean airspeed difference of just one-quarter of a knot is operationally insignificant. Subject pilots maintained assigned airspeeds equally well when they performed approaches using the Baseline display, the MAS 1 display, and the MAS 2 display $(p>0.05)$ and when they performed different approach types using different types of displays $(p$ $>0.05$ ).

Overall, the analyses of the RMSE values associated with the SSS Flight Experiment's test conditions indicated that flight path parameter deviations did not increase when self-separation and sequencing tasks were added to a baseline GPS instrument approach. In other words, subject pilots participating in the SSS Flight Experiment were able to fly an aircraft equally well when they performed a baseline GPS instrument approach and when they performed SATS HVO approaches.

\section{Adherence to Practical Test Standards for the Instrument Rating}

To assess subject pilots' adherence to the PTS for the Instrument Rating, the duration associated with each PTS "bust" that occurred during the experiment's test conditions was calculated. For each subject pilot, one duration was calculated for each parameter (i.e., altitude, airspeed, vertical velocity, and XTE) using the data recorded during a single test condition.

All subject pilots successfully adhered to the Course Deviation Indication (CDI) PTS for the Instrument Rating 100 percent of the time. For the other flight path parameters, PTS "bust" durations were analyzed using a series of $2 \times 3$ repeated measures ANOVAs. The results of the ANOVAs revealed that subject pilots adhered to the PTS for the Instrument Rating for altitude, airspeed, and vertical velocity equally well when they performed straight-in, intrail approaches and when they performed simultaneous arrival approaches $(p>$ 0.05 ); when they performed approaches using the Baseline display, the MAS 1 display, and the MAS 2 display $(p>0.05)$; and when they performed different approach types using different types of displays $(p>0.05)$. These findings indicate that the abilities of pilots to fly an aircraft during GPS instrument approaches were not negatively impacted by the addition of self-separation and sequencing tasks.

\section{Subjective Assessments of Workload}

For each subject pilot, the two AFFTC Subjective Workload Estimate Scale ratings associated with a given test condition were averaged together to yield a set of six mean workload ratings, and the two Modified CooperHarper Rating Scale ratings associated with a given test condition were averaged together to yield a set of six mean workload ratings. As reported below, nonparametric tests were employed as a conservative method for analyzing workload ratings associated with discrete rating scale items.

A series of Wilcoxon Tests and a series of Friedman Tests were performed on the mean AFFTC workload ratings and on the mean Modified Cooper-Harper workload ratings to determine if subject pilots reported experiencing different levels of workload when performing the two types of approaches, when using the different display types, and when using the different display types during the two type of approaches $[17,18]$. These tests revealed that subject pilots reported experiencing equivalent levels of workload when performing the straight-in, intrail approaches and the simultaneous arrival approaches; when using the Baseline display, the MAS 1 display, and the MAS 2 display; and when performing the two type of approaches while using the three different display types $(p>$ 0.05 ). These results suggest that the subject pilots' perceptions of workload were not negatively influenced by the additional tasks of self-separating and sequencing during GPS instrument approaches.

\section{Conclusions}

Primary components necessary for implementing the SATS HVO Con Ops include the SCA, AMM, CDTI, and related SATS HVO IAPs. Two critical pilot tasks integral to the Con Ops include self-separation and sequencing. Therefore, the focus of the SSS Flight Experiment was to determine the feasibility of GA pilots self- 
separating and sequencing their ownship aircraft for an approach as well as during an instrument approach at a simulated non-towered, non-radar equipped airport during simulated IMC. As a result of this focus, the experiment concentrated on assessing the impact of the self-separation and sequencing tasks on subject pilots' performance of GPS instrument approaches, and perceptions of workload, during simulated $\mathrm{IMC}$. The additional information displayed to subject pilots participating in this experiment included CDTI, Proceed/Hold, and, when using the MAS 2 display, conflict detection, alerting, and prevention information.

Quantitative analyses of the data acquired during the SSS Flight Experiment suggest that a GA pilot's ability to fly an instrument approach is not adversely affected by the additional tasks of selfseparating and sequencing using SATS HVO IAPs. Furthermore, analyses of qualitative data collected during the SSS Flight Experiment indicate that the level of workload experienced by a pilot, while flying an instrument approach and performing selfseparation and sequencing tasks using SATS HVO IAPs, is no greater than that experienced when performing baseline (i.e., current day) approaches.

During the SSS Flight Experiment, subject pilots successfully self-separated and sequenced using two versions of CDTI formats. Had this experiment been conducted in actual IMC with real traffic, the subject pilots would not have noticed a difference between the presentation of simulated traffic and real traffic on the displays. Also, had the flight experiment been conducted at an actual nontowered, non-radar airport, the subject pilots would not have seen a variance in the output of the Garmin 430 GPS or the SR22X's flight instruments. Therefore, the results of the SSS Flight Experiment suggest that self-separation and sequencing using SATS HVO IAPs are viable in actual IMC during actual GPS approaches into a non-towered, nonradar equipped airport.

Integration of the self-separation and sequencing tasks with the SCA and AMM are addressed in future simulation and flight experiments. Since conducting the SSS Flight Experiment, the SATS HVO Con Ops has been refined [19]. However, the findings of the SSS Flight Experiment are still applicable to current and future SATS HVO research since pilots will still be required to perform similar tasks during a SATS HVO approach.

In the new SATS HVO Con Ops, aircraft begin the approach on one of the two base leg IAF's instead of at the IF. As in the SSS Flight Experiment, the calculation of when the ownship aircraft can leave the approach fix inbound is made when the lead aircraft is inbound on the approach past the IF. If the ownship aircraft must hold for traffic, it will now hold at the IAF. Holding at the IAF allows a larger capacity within the SCA because aircraft can hold at either of the approach "T's" IAFs. The new Con Ops, similar to the SSS Flight Experiment, will accommodate intrail approaches and simultaneous arrival approaches.

Instead of the rudimentary text box that displayed information needed by the pilot to determine when to begin the approach or hold during the SSS Flight Experiment, the concept of a SATS HVO Pilot Advisor has evolved. In addition to providing pilots with SATS HVO procedure information and traffic related advisories, the SATS HVO Pilot Advisor will also be used to prompt pilots to request a sequence number; identify the traffic aircraft to follow; monitor approach procedure conformance; advise of the proper entry procedure into the SCA; and advise the pilot when to descend and to begin the approach [19].

A human-in-the-loop (HITL) simulation experiment and a second flight experiment will be used to evaluate the latest SATS HVO Con Ops. These research endeavors will assess the integration of pilot self-separation and sequencing tasks with operations with the AMM within the SCA by comparing the SATS HVO Con Ops to the one-inone-out procedural control environment available today in order to determine: 1 ) if pilots can safely and proficiently fly an aircraft while performing SATS HVO procedures, and 2) if pilots perceive that workload, while using HVO procedures and tools, is no greater than flying in today's system [20].

The HITL simulation experiment was completed in May 2004, and the next SATS HVO flight experiment is scheduled to be completed during the fall of 2004 . The SSS Flight Experiment, the HITL simulation experiment, and the follow-on flight experiment are all intended to serve as evaluations of normal operations. A final 
flight demonstration of the SATS HVO Con Ops will be conducted in the spring of 2005, and future research endeavors will be conducted in order to address non-normal operations related to the SATS HVO Con Ops.

\section{References}

[1] Durham, M., C. Jeremiah, 2001, Small Aircraft Transportation System Program Plan (Draft), Hampton, VA, NASA Langley Research Center.

[2] NASA Langley Research Center, 2002, Small Aircraft Transportation Information (NP-2002-0716-LaRC) [Brochure], Hampton, VA.

[3] NASA Langley Research Center, 2002, Small Aircraft Transportation System Program 2010 Concepts of Operations Document (Version 1.0), Hampton, VA.

[4] Federal Aviation Administration, 1998, Instrument Rating Practical Test Standards for Airplane (FAA-S-8081-4C with Changes 1 and 2), Washington, D.C., U.S. Department of Transportation.

[5] Howell III, C., K. Shelton, B. Fisher, D. Gallaher, S. Johnston, H. Rush, C. Smith, D. Trometta, R. Kimbrel, 2003, The NASA Langley Research Center's General Aviation Baseline Research System, $22^{\text {nd }}$ IEEE AIAA Digital Avionics Systems Conference, Indianapolis, IN.

[6] National Aerospace Laboratory (NLR), 2003, Traffic Manager (Version 5.40) [Computer software], Hampton, VA, NASA Langley Research Center.

[7] Blount, E., J. Van Pelt, 2003, Small Aircraft Transportation System Higher Volume Operations Self-Separation and Sequencing Flight Test MultiFunction Display Software (Version 1.2) [Computer software], Hampton, VA, NASA Langley Research Center.

[8] Myer, R., 2003, Avidyne Multifunction Display Reader and a MFD Simulator [Computer software], Hampton, VA, Raytheon Consolidated Information Technology Services, NASA Langley Research Center.

[9] Bussink, F. J., 2003, SATS HVO SSS Fight Test Traffic Manager (Version 5.46k) [Computer software], Hampton, VA, National Institute of Aerospace, NASA Langley Research Center.

[10] Meyer, A., 2002, X-system (Version 6.21) [Computer software], Columbia, SC, Laminar Research.

[11] Albricci, L., 2002, Cirrus SR20 (Version1.1 XP6) [Computer software], Available: www.Xplane.org/detailed/2668.shtml

[12] Federal Aviation Administration, 2000, Terminal Arrival Area (TAA) Design Criteria (8260.45A), Washington, D.C., U.S. Department of Transportation.

[13] Jeppesen Sanderson, Inc., 2002, FlightMap IFR North America (Version 8.51) [Computer software], Englewood, CO, Author.

[14] Ames, L. L., E. J. George, 1993, Revision and Verification of a Seven-Point Workload Estimate Scale (AFFTC-TIM093-01), Edwards Air Force Base, CA, Air Force Flight Test Center.

[15] Wierwille, W. W., J. G. Casali, 1983, A Valid Rating Scale for Global Mental Workload Measurement, Proceedings of the Human Factors Society 27th Annual Meeting, pp. 129-133.

[16] Keppel, G., 1991, Design and Analysis: A Researcher's Handbook (3rd ed.), Englewood Cliffs, NJ, Prentice-Hall, Inc.

[17] Norusis, M. J., 1993, SPSS $®$ for Windows ${ }^{\mathrm{TM}}$ : Base System User's Guide, Release 6.0, Chicago, IL, SPSS Inc.

[18] Winer, B. J., D. R. Brown, K. M. Michels, 1991, Statistical Principles in Experimental Design ( ${ }^{\text {rd }}$ ed.), New York, McGraw-Hill, Inc.

[19] Adams, C., M. Consiglio, K. Jones, D. Williams, T. Abbott, 2003, Development of the SATS HVO Operational Concept: Nominal Operations, Hampton, VA, NASA Langley Research Center.

[20] Williams, D., J. Murdoch, 2004, Higher Volume Operations 2 (HVO-2) Flight Test, Operational Safety Review for the Airworthiness and Safety Review Board conducted at NASA Langley Research Center, Hampton, VA. 